\title{
PERCEPÇÃO DE ACOMPANHANTES SOBRE A CRIANÇA INTUBADA EM UTI PEDIÁTRICA
}

Juliane Gequelin¹, Krícia Frogeri Fernandes², Giordano Pedro de Oliveira ${ }^{3}$, Ana Maria Dyniewicz ${ }^{4}$

${ }^{1}$ Psicóloga. Hospital Infantil Waldemar Monastier. Campo Largo-PR-Brasil.

${ }^{2}$ Psicóloga. Tribunal de Justiça do Paraná. Curitiba-PR-Brasil.

${ }^{3}$ Enfermeiro. Hospital Infantil Waldemar Monastier. Campo Largo-PR-Brasil.

${ }^{4}$ Enfermeira. Doutora em Enfermagem. Universidade Federal do Paraná. Curitiba-PR-Brasil.

RESUMO: A intubação traz significados para acompanhantes em Unidade de Terapia Intensiva Pediátrica, pois ocasiona alteração da imagem corporal da criança, interfere na comunicação, sugestionando gravidade no quadro clínico. O objetivo foi analisar a percepção do acompanhante sobre a criança intubada, entre julho e outubro de 2011, em um hospital de Campo Largo/Paraná-Brasil. Foi realizada pesquisa de abordagem qualitativa, por meio de entrevista semiestruturadas, com oito acompanhantes. As categorias, a partir da análise de conteúdo, foram: Impacto com a gravidade da doença e a intubação; A intubação como canal de vida e Atitudes e comportamentos do acompanhante. Conclui-se que a intubação é percebida inicialmente como momento de comoção e abalo com o ambiente e recursos da unidade. Alguns acompanhantes transpõem para si possíveis sensações da criança. Também, é entendida como meio de sobrevivência e os acompanhantes desenvolvem estratégias de enfrentamento, mostrando-se resilientes e encarando como aprendizagem para vida.

DESCRITORES: Criança; Pediatria; Intubação.

\section{COMPANIONS' PERCEPTIONS REGARDING THE INTUBATED CHILD IN PEDIATRIC ICU}

\begin{abstract}
Intubation brings meanings for companions in the Pediatric Intensive Care Unit, as it causes change of the child's body image, interferes in communication, and suggests severity in the clinical picture. This study aimed to analyze the companion's perception regarding the intubated child, and was undertaken between July and October 2011, in a hospital in Campo Largo, in the Brazilian state of Paraná. A study with a qualitative approach was undertaken, using semi-structured interviews, held with eight participants. The categories, based on the content analysis, were: 'Impact caused by the severity of the illness and the intubation'; 'Intubation as a channel for life' and 'The companion's attitudes and behaviors'. It is concluded that the intubation is initially perceived as a period of commotion and shock caused by the unit's environment and resources. Some companions transpose to themselves the child's possible feelings. Also, it is understood as a means of survival, and the companions develop coping strategies, showing themselves to be resilient, and viewing it as learning for life.
\end{abstract}

DESCRIPTORS: Child; Pediatrics; Intubation

\section{PERCEPCIÓN DE ACOMPAÑANTES SOBRE EL NIÑO INTUBADO EN UTI PEDIÁTRICA}

RESUMEN: La intubación trae significados para acompañantes en Unidad de Terapia Intensiva Pediátrica, pues ocasiona alteración de la imagen corporal del niño, interfiere en la comunicación, sugestionando gravedad en el cuadro clínico. El objetivo Del estudio fue analizar la percepción del acompañante sobre el niño intubado, entre julio y octubre de 2011, en un hospital de Campo Largo/ Paraná, Brasil. Fue realizada investigación de abordaje cualitativo, por medio de entrevista semiestructurada, con ocho acompañantes. Las categorías, con base en el análisis de contenido, fueron: Impacto con la gravedad de la enfermedad y la intubación; La intubación como canal de vida y Actitudes y comportamientos del acompañante. Se concluye que la intubación es percebida inicialmente como momento de comoción y shock con el ambiente y recursos de la unidad. Algunos acompañantes transponen para sí posibles sensaciones del niño. También es entendida como medio de sobrevivencia y los acompañantes desarrollan estrategias de afrontamiento, revelando resiliencia y mirando como aprendizaje para vida.

DESCRIPTORES: Niño; Pediatría; Intubación. 


\section{INTRODUÇÃO}

Nas últimas décadas tem-se observado avanço exponencial da tecnologia em saúde, o que gera impacto na maneira do ser humano relacionarse com a doença e a hospitalização. O humano é ser bio-psico-social-espiritual e qualquer alteração em uma destas dimensões ocasionam repercussões nas demais. O processo de doença e hospitalização em si mesmo ou em uma pessoa próxima é gerador de adaptações, mudanças e mobilização de conteúdos subjetivos. Quando se trata de criança, internada em Unidade de Terapia Intensiva Pediátrica (UTIP), as emoções podem ser mais intensas.

Há pesquisas que tratam da vivência e dos sentimentos gerados nas famílias com crianças internadas em UTIP(1). Nesse sentido, destacamos o procedimento de intubação e a percepção dos familiares sobre o mesmo. Em nossa prática percebemos, pelo relato dos acompanhantes, que este se trata de procedimento que gera ansiedade, incertezas e a própria possibilidade de se deparar com a morte.

Por ser um setor complexo, as UTI mobilizam toda a infraestrutura hospitalar e serviços de apoio $^{(2)}$, tem rotina própria e diversos estressores físicos, ambientais, psicológicos e sociais. Entre os recursos utilizados têm-se a ventilação mecânica, a qual pode ser definida, de acordo com o III Consenso de Ventilação Mecânica, como suporte ventilatório para o tratamento de pacientes com insuficiência respiratória aguda ou crônica agudizada. Objetiva a manutenção das trocas gasosas, correção da hipoxemia e da acidose respiratória. A ventilação invasiva (processo de intubação) utiliza-se de uma prótese - conhecida também por cânula ou tubo - orotraqueal, nasotraqueal ou cânula de traqueostomia ${ }^{(3)}$.

Diante disso, a UTIP pode se apresentar como espaço assustador, principalmente pela quantidade de aparelhos. O medo e a ameaça da morte são reações emocionais presentes em pais de crianças internadas em UTIP ${ }^{(1,4-5)}$. Desde a antiguidade este tema é envolto de fantasias, incertezas, medos e repulsa; mobiliza sentimentos de desespero, tristeza, indignação, raiva, culpa, dificuldade de aceitação ${ }^{(6)}$.

Durante o ciclo vital o ser humano vivencia estressores que demandam a busca de soluções para enfrentar as dificuldades, sendo o adoecimento um destes aspectos. Pessoas que passam por situações adversas podem enfrentá-las com sucesso e saírem fortalecidas, enquanto que para outras essa experiência de enfrentamento e fortalecimento não se faz presente. Esta capacidade humana de enfrentar, superar e ser fortalecido ou transformado por experiências e/ ou situações adversas é denominado resiliência ${ }^{(7)}$. Há também outras formas de enfrentamento, tal como a crença na dimensão espiritual. Deste modo, a doença pode mobilizar no ser humano a fé, como via de cura ou o enfrentamento da situação de dificuldade ${ }^{(8)}$.

Diante do exposto este artigo objetiva descrever a percepção do acompanhante sobre a criança intubada em UTIP.

\section{MÉTODO}

O presente estudo foi desenvolvido a partir de pesquisa de abordagem qualitativa realizada com acompanhantes de crianças intubadas, internadas em Unidade de Terapia Intensiva Pediátrica de um hospital público do estado do Paraná. A amostra foi aleatória, tendo como critério de inclusão: acompanhantes de crianças internada na UTIP entre 28 dias e 14 anos de idade e em ventilação mecânica, no período de coleta de dados e que se dispusessem a responder a um questionário semiestruturado. A coleta de dados foi realizada entre os meses de julho a outubro de 2011, após aprovação do projeto no Comitê de Ética em Pesquisa em Seres Humanos - Secretaria Estadual de Saúde do Paraná/Hospital do Trabalhador, sob o número 344/2011 de 30 de junho de 2011. Os participantes foram informados sobre os objetivos da pesquisa, os aspectos éticos e a seguir assinaram o termo de consentimento livre e esclarecido.

O instrumento para coleta de dados continha dados de identificação do entrevistado e o questionamento "O que significa para você ver a criança intubada?". Os dados foram coletados por dois pesquisadores: um realizava a entrevista e o outro a registrava. Os registros foram analisados a partir de análise de conteúdo, baseada na perspectiva fenomenológica. O método fenomenológico preocupa-se com o significado das vivências a partir do sujeito 
que as experiencia. Algumas etapas que foram seguidas nesta pesquisa, a saber: o sentido do todo; discriminação das unidades de significado; transformação das expressões cotidianas do sujeito em linguagem psicológica; e, por fim, a etapa de síntese das unidades de significado transformadas em proposição ${ }^{(9)}$.

A partir da análise dos dados, foram levantados alguns dados sobre o perfil dos acompanhantes entrevistados, além da composição de categorias e subcategorias para análise. Os entrevistados foram identificados pela letra " $\mathrm{E}$ " seguida por uma ordem numérica.

\section{RESULTADOS}

Participaram do estudo oito acompanhantes, todas do sexo feminino, adultas, com média de três filhos e diferentes graus de instrução, desde Ensino Fundamental incompleto até Nível Superior com pós-graduação. Seis acompanhantes eram as mães das crianças e duas eram avós. Por meio dos dados de identificação das entrevistadas, observa-se que apenas uma mãe comenta que "não está trabalhando" e outra relata que é "do lar"; as demais acompanhantes mencionaram seus trabalhos: professora, repositora em supermercado e auxiliar de produção. Todas referiram que estavam afastadas por conta do período de hospitalização da criança na UTIP. Houve diferentes níveis socioeconômicos, com média de 2,8 salários mínimos de renda. Ainda informaram ser advindas de diferentes regiões do Estado do Paraná.

No quadro 1 são descritas as três categorias extraídas de análise de conteúdo com suas respectivas subcategorias.

A categoria 1, "Impacto com a gravidade da doença e a intubação", refere-se ao choque ocorrido no acompanhante com a gravidade da doença e a intubação. Na subcategoria "Susto com o ambiente e os recursos da UTIP" os relatos dos acompanhantes entrevistados exemplificam aspectos do desespero, não somente pelo ambiente da UTI, mas pela intubação em si, que é um recurso tecnológico utilizado nestes ambientes:

Me assustei, porque qualquer pessoa se assusta. $A h$, a gente tem um impacto. (E1)

Nunca tinha visto isso! Levei um choque! Eu me lembro dele roxo no hospital e depois foi colocado com este aparelho. (E4)

Nervosismo, desespero, aflição, pânico. (E8)

Na subcategoria "Transposição para o acompanhante de sensações da intubação", observou-se por meio dos relatos dos acompanhantes que alguns deles transpuseram para si as sensações da intubação, isto é, apontam sensações imaginadas ou percebidas por eles que são vivenciadas pela criança e sentem em si mesmos. As falas abaixo exemplificam este aspecto:

A gente sabe que é o meio dela respirar, mas a gente se sente sufocada, pensando como é respirar. (E1)

E ver ele com os aparelhos dá um ruim. (E4)

O tubo deve incomodar. (E5)

Quadro 1 - Categorias e subcategorias advindas da análise de conteúdo. Campo Largo-PR-Brasil, 2013

\begin{tabular}{|c|c|}
\hline CATEGORIAS & SUBCATEGORIAS \\
\hline \multirow{3}{*}{ 1. Impacto com a gravidade da doença e a intubação } & Susto com o ambiente e os recursos da unidade \\
\hline & Transposição para o acompanhante de sensações da intubação \\
\hline & Iminência da morte \\
\hline \multirow{3}{*}{ 2. A intubação como canal de vida } & O tubo como meio de sobrevida \\
\hline & Experiências anteriores \\
\hline & Obtendo informações sobre a intubação \\
\hline \multirow{3}{*}{ 3. Atitudes e comportamentos do acompanhante } & Resiliência \\
\hline & Espiritualidade \\
\hline & Aprendizagem \\
\hline
\end{tabular}


Acho que não é nada confortável e pra quem usa é pior. Sinto peso de ficar aqui dentro da UTI, quando dá o meu limite eu tenho que sair. (E7)

É difícil de falar, a gente mais sente. (E8)

De acordo com a subcategoria "Iminência da morte", verificou-se que quando os acompanhantes vivenciam ao lado da criança o adoecimento e a hospitalização, principalmente em espaço que requer cuidados especializados como o de UTI, é comum surgirem sentimentos de perda e a presença do medo da morte. Os relatos a seguir demonstram o exposto:

Parece que ele está morto. (E4)

Da mesma forma que ele está bem, pode ser que não esteja. (E5)

[...] e tem o medo do falecimento, que nem aconteceu com a minha filha. (E7)

Já parece que a filha da gente tá morrendo. $O$ pensamento de que sua filha vai morrer, só isso. (E8)

Quanto à categoria 2, por meio das entrevistas realizadas, percebeu-se que seis das oito acompanhantes relacionaram a intubação com a salvação e a sobrevida da criança, conforme a categoria "A intubação como canal de vida". Na subcategoria "O tubo como meio de sobrevida", as seguintes falas exemplificam este fato:

É para salvar [...]. Se não tivesse esse tubo, talvez nem tivesse salvado ela. (E3)

Sem o tubo não tem como viver. Se não fosse o tubo talvez já tivesse se afogado. (E7)

Agora estou me acostumando, sei que é para ela respirar. Sem aquilo [ela] não tem como ela respirar, é o melhor para ela. (E8)

As experiências anteriores em ter um familiar intubado foram relatadas em quatro entrevistas, segundo a subcategoria "Experiências anteriores". Alguns exemplos:

Não me preocupei tanto, já tive meu pai intubado. (E2)

Nada mais é novidade. Já passei muitas vezes, vira rotina. Não é mais problema. Meus tios e filhos já colocaram [o tubo] por problemas na respiração, né? (E7)

Já vi minha mãe intubada, mas a criança é diferente. (E1)

As informações obtidas acerca do processo de intubação foram mencionadas por três acompanhantes, de acordo com a subcategoria "Obtendo informações sobre a intubação". Duas destas três acompanhantes teceram comentários relacionados à falta de informações, e em uma entrevista a informação oferecida mostrouse importante para tranquilizar a familiar, respectivamente:

Eu não sabia por que colocaram aquele tubo. (E3)

A gente escuta muita coisa, como o risco de falecer. (E5)

Fico mais calma após as informações dadas pela médica e psicóloga. (E2)

"Atitudes e comportamentos do acompanhante" compôs a categoria 3 e refere-se às atitudes e comportamentos relatados nas entrevistas diante da criança intubada. "Resiliência", "Espiritualidade" e "Aprendizagem" foram as subcategorias analisadas.

As reações e as atitudes dos acompanhantes quando defrontados com a realidade da criança intubada provocaram demonstrações de comportamentos adaptativos e superativos. $\mathrm{Na}$ subcategoria "Resiliência", este aspecto vai ao encontro deste construto que é a capacidade do indivíduo deparar-se com situações desfavoráveis e desenvolver a capacidade de enfrentá-las de modo positivo. Os relatos a seguir demonstram esta questão: 
Você tem que ter um controle, tem que raciocinar, ter calma, manter controle. É preciso saber discernir e compreender. (E1)

\section{Temos que tentar melhorar. (E7)}

Outros dois relatos mostram que o otimismo pode ser um artefato para comportamento não necessariamente resiliente, mas como possível negação diante da realidade adversa. Segue os exemplos em que os acompanhantes falam brevemente dos sentimentos de tristeza e preocupação, mas logo em seguida apontam a expectativa de que tudo vai dar certo:

Sentimento de tristeza de ver ele com os aparelhos, mas sei que ele vai sair dessa. Lembro dele dando risada. (E4)

A gente fica preocupada, mas acho que não vai acontecer nada. (E6)

A busca por significado, que compreende a subcategoria "espiritualidade" pode ser claramente percebida no seguinte relato:

Precisa de uma compreensão espiritual. A fé da gente, a religião ajudou muito. Se o espírito está fraco a carne não compreende. A palavra fala que a gente tem que estar preparado para morte. E isso só veio confirmar que realmente a gente tem que estar preparado. (E1)

Na subcategoria "Aprendizagem" os relatos mostram sensações diversas dos acompanhantes, dentre elas a capacidade de adaptação às situações tal como a seguinte fala:

\section{Vai indo a gente acostuma, tem que conviver. (E7)}

No entanto, se destaca aqui a capacidade de aprendizagem dentro da diversidade, e o sofrimento dela decorrente parece provocar a construção de uma consciência reflexiva sobre questões de vida, saúde e doença, tal como foi dito:

Isso aí [intubação] para mim foi uma lição, para crescimento mesmo. Uma aprendizagem. Na prática tudo é diferente. (E1)

\section{DISCUSSÃO}

Todas as acompanhantes das crianças internadas na UTIP eram do sexo feminino, o que corrobora com os dados encontrados na literatura, a respeito do feminino no papel de cuidador.

O papel feminino, como parte da natureza feminina associado à representação da abnegação e amorosidade, é determinante para que a responsabilidade do cuidado seja delegada à mulher ${ }^{(10: 293)}$.

Sobre a atenção à criança e o trabalho as acompanhantes informam mudanças, isto comprova que quando um membro da família é hospitalizado, o sistema familiar como um todo é abalado em sua homeostase, ocorrendo troca de papéis. As referidas acompanhantes passam a acumular funções entre ser cuidadora da criança hospitalizada e mantenedora do lar (vínculo empregatício). Deste modo, a família que representa um grupo social que mantêm rotinas e padrões relacionais próprios tem rupturas quando ocorre a hospitalização de um de seus membros (no caso de crianças), observam-se alterações na dinâmica familiar e diferentes reações emocionais ${ }^{(4)}$.

Quando a internação ocorre de maneira inesperada o estresse ainda é maior, pois existe associação com perdas e morte. Geralmente as UTIs são locais com aparatos tecnológicos que procuram trazer benefícios à criança, mas também podem se tornar um ambiente assustador devido aos aparelhos, ruídos e a impessoalidade ${ }^{(4-5)}$.

Afinal, a situação de hospitalização é algo único e que não faz parte dos projetos de vida de uma pessoa. Sendo assim,

toda e qualquer invasão no espaço vital é algo aversivo que, além do caráter abusivo, apresenta ainda componentes de dor e desalento ${ }^{(11: 68)}$.

Estar como acompanhante em UTI pode ser experienciada por sentimentos de isolamento e privação, não apenas pelo distanciamento da rotina social e familiar, mas pela própria estrutura física e funcional do serviçO ${ }^{(1)}$.

No mesmo sentido, os acompanhantes de crianças internadas em UTI podem sentir angústia, 
desânimo, preocupação e incerteza relacionadas à doença e, além disso, o medo da perda do filho torna-se uma ameaça real ${ }^{(12)}$. Ademais, grande parte dos acompanhantes acredita que a UTI seja um local hostil, negativo, que não produz saúde, no qual há dor, sofrimento e morte, por este ser um ambiente em que a gravidade, a invasividade e o risco de morte estão presentes ${ }^{(13)}$.

A partir dos discursos das acompanhantes das crianças, pode-se dizer que há uma relação entre o investimento tecnológico e a confiança dos familiares. A UTI é um ambiente de alta tecnologia, com diversos recursos disponíveis para melhor atender o paciente; trata-se de uma área crítica para internação de pacientes graves que necessitam atenção profissional contínua e especializada, materiais específicos e tecnologias necessárias para realização de diagnóstico, monitorização e terapia(2). Como esta pesquisa foi realizada em um hospital que atende exclusivamente a rede pública de saúde, estes resultados parecem demonstrar que há confiança dos familiares nos recursos tecnológicos disponibilizados à sociedade por meio do Sistema Único de Saúde.

Houve discursos de acompanhantes de crianças em UTIP mostrando que experiência com familiar intubado serviu para amenizar o impacto do acompanhante diante deste processo de intubação. Contudo, a significação atribuída vai depender da intensidade e do contexto da situação anterior. Se for percebida como extremamente traumática provavelmente trará consigo seqüelas, caso contrário, o fato pode contribuir para amenizar o sofrimento ${ }^{(14)}$.

Estudos mostram que os acompanhantes, em círculos de discussão com profissionais, se sentiam a vontade para falar sobre o momento que estavam passando com seus filhos e assim levantavam suas dúvidas a respeito de assuntos que os inquietavam, como por exemplo, em relação à doença do seu filho. Deste modo, percebeu-se que acompanhantes estão interessados em aprender e, com isso, permitem aos profissionais de saúde oferecer orientações a estas pessoas. Ademais, o desejo dos acompanhantes em interagir com a equipe de saúde, dispondo-se a ajudar nos cuidados com o filho, fornecendo informações e trocando experiências com os profissionais ${ }^{(12,15)}$.

O processo de comunicação em UTI é fundamental para promover a humanização em ambiente hospitalar. Para que ocorra satisfatoriamente é preciso que as informações sejam transmitidas e o destinatário as receba e as compreenda ${ }^{(4,16)}$. O recebimento de informações fidedignas a respeito do paciente constitui-se de motivo de satisfação e segurança e contribui para a sensação de tranqüilidade da família. Porém, deve-se cuidar com a sobrecarga de informações, uma vez que isto pode prejudicar o entendimento de fatos e o estabelecimento de vínculo com familiares e acompanhantes ${ }^{(4)}$.

Nos relatos desta pesquisa é possível notar que existe uma tentativa de superar as adversidades, indicando um padrão de adaptação a presente adversidade. A resiliência pode, portanto, ser considerada fator de proteção para a adaptação do indivíduo às exigências do cotidiano. $\mathrm{O}$ mecanismo da negação (total ou parcial) geralmente é temporário e utilizado por quase todos os pacientes, em fase inicial ou posterior de adoecimento. Uma forma saudável de lidar com o sofrimento, comparando a negação com um pára-choque, protegendo o paciente/familiar e permitindo a recuperação com o tempo ${ }^{(17)}$.

A intensidade de sentimentos ocasionada pela situação de se defrontar com a visão de uma criança intubada pode suscitar reações em direção à espiritualidade. No cotidiano do trabalho em UTIP, constatam-se diversas manifestações desta natureza nos acompanhantes de crianças internadas. Constitui-se de um sistema de crenças que enfocam elementos intangíveis, que transmite vitalidade e significado para a vida. Sobre este tema aponta-se ${ }^{(18)}$ que o ser humano ao buscar significado para a vida pode ou não incluir participação religiosa formal.

Percebe-se aqui a liberdade do poder criativo advindo das experiências do acompanhante, ao conviver com a dinâmica de atenção à criança e ir paulatinamente compreendendo e reelaborando os acontecimentos. Fato que pode ter sido facilitado pela relação com os profissionais da UTIP. Esta afirmação se encontra no fato de que situação de aproximação com a morte estimula novos significados e sentidos à vida, os quais podem provocar mudanças no cuidador, tais como desenvolver e expressar novas atitudes, valores e hábitos ${ }^{(19)}$. Desta forma, é importante que os profissionais de saúde que trabalham em UTIP ofereçam apoio também aos acompanhantes das crianças internadas, uma vez 
que a família, quando bem amparada, ajuda-se e pode ajudar na recuperação das mesmas ${ }^{(15)}$.

\section{CONCLUSÃO}

Este trabalho objetivou identificar as diferentes percepções que os acompanhantes tiveram ao ver sua criança intubada. A pesquisa revelou que a experiência da intubação é percebida inicialmente pelos acompanhantes como um momento de impacto, em que estes se mostram assustados com o ambiente e os recursos da UTIP.

Após este impacto inicial a intubação é entendida como um canal de vida, o meio de sobrevivência da criança, o que também depende de significações de experiências familiares anteriores e das informações fornecidas pela equipe sobre o processo de intubação. Por fim, a pesquisa apontou que os acompanhantes desenvolvem estratégias de enfrentamento da situação adversa (intubação), mostrando-se resilientes e utilizando-se da espiritualidade, encarando a situação como aprendizagem para a vida.

Os resultados da pesquisa apontam algumas diretrizes para o trabalho da equipe diante da intubação. Ficou evidenciado que a informação/ comunicação durante o processo de intubação permite ao acompanhante ter maior compreensão do que está acontecendo com a criança e tranqüilidade diante da situação. Por fim, cabe ressaltar que estratégias de enfrentamento diante de situações estressoras foram evidenciadas, mostrando que os acompanhantes encontram meios saudáveis de lidar com a intubação.

\section{REFERÊNCIAS}

1. Morais GSN, Costa SFG. Experiência existencial de mães de crianças hospitalizadas em unidade de terapia intensiva pediátrica. Rev Esc Enferm USP. 2009;43(3):639-46.

2. Brasil. Agência Nacional de Vigilância Sanitária. Resolução n. 7, de 24 de fevereiro de 2010. Dispõe sobre os requisitos mínimos para funcionamento de Unidades de Terapia Intensiva e dá outras providências. Brasília; 2010.

3. Carvalho CRR, Toufen CJ, Franca SA. Ventilação mecânica: princípios, análise gráfica e modalidades ventilatórias. J. Bras. Pneumol. 2007;33(2):54-70.
4. Souza RP. Manual - rotinas de humanização em medicina intensiva. São Paulo: Atheneu; 2010.

5. Wyzykowski C, Santos RS. A reação materna diante da internação do filho na terapia intensiva pediátrica: contribuições para a prática da enfermagem. Rev. SOBEP. 2007;7(2):75-82.

6. Kovács MJ. Morte e desenvolvimento humano. São Paulo: Casa do Psicólogo; 2010.

7. Llergo ICA, Araiza YIS. Manifestación de la resiliencia como factor de protección em enfermos crônicos terminales hospitalizados. Rev. iberoam. diagn. eval. psicol. 2009;2(17):24-32.

8. Simonetti A. Manual de psicologia hospitalar: o mapa da doença. São Paulo: Casa do Psicólogo; 2011.

9. Martins J, Bicudo MAV. A pesquisa qualitativa em psicologia: fundamentos e recursos básicos. São Paulo: Centauro; 2005.

10. Cortes LF, Vieira LB, Landerdahl MC, Padoin SMM. Construção do feminino e do masculino: compreensão de uma equipe de enfermagem. Cogitare enferm. 2011;16(2):289-95.

11. Angerami-Camon VA. O psicólogo no hospital. São Paulo: Pioneira Thomson Learning; 2004.

12. Hayakawa LY, Marcon SS, Higarashi IH. Alterações familiares decorrentes da internação de um filho em uma unidade de terapia intensiva pediátrica. Rev. Gaúcha Enferm. 2009;30(2):175-82.

13. Pinho LB, Santos SMA. Dialética do cuidado humanizado na UTI: contradições entre o discurso e a prática profissional do enfermeiro. Rev Esc Enferm USP. 2008;42(1):66-72.

14. Chiattone HBC. A criança e a hospitalização. In: Angerami-Camon VA. O psicólogo no hospital. São Paulo: Pioneira Thomson Learning; 2004. p. 23-100.

15. Dutra C, Neves N, Barreto M, Souza M, Mayer E, Cupertino $M$, et al. Programa de atendimento à família no ambiente hospitalar: uma ação de humanização junto aos acompanhantes das crianças internadas no Hospital São Sebastião de Viçosa, MG. ParticipAção; 2012. p.54-60.

16. Schneider CC, Bielemann VLM, Sousa AS, Quadros LCM., Kantorski LP. Comunicação na unidade de tratamento intensivo, importância e limites - visão da enfermagem e familiares. Cienc. cuid saude. 2009;8(4):531-9.

17. Kübler-Ross E. Sobre a morte e o morrer. São Paulo: WMF Martins Fontes; 2008.

18. Giovelli G, Luhring G, Gauer GJC, Calvetti PU, Gastal 
$\mathrm{R}$, Trevissan C, et al. Espiritualidade e religiosidade: uma questão bioética? Rev. SORBI. 2008;1(5):1-12.

19. Fratezi FR, Gutierrez BAO. Cuidador familiar do idoso em cuidados paliativos: o processo de morrer no domicílio. Ciênc. saúde colet. 2011;16(7):3241-8. 